\title{
SENSOR ARRAYS: AN INSPIRED IDEA OR AN OBJECTIVE MEASUREMENT OF ENVIRONMENTAL ODOURS?
}

\author{
R. M. Stuetz* and J. Nicolas** \\ * School of Water Sciences, Cranfield University, Cranfield MK43 OAL, UK \\ ** Dept of Environmental Monitoring, Fondation Universitaire Luxembourgeoise, Avenue de \\ Longwy, 185 B6700-Arlon, Belgium
}

\begin{abstract}
The measure of annoyance odours from sewage treatment, landfill and agricultural practise has become highly significant in the control and prevention of odorous emissions from existing facilities and is crucial for new planning applications. Current methods (such as GC-MS analysis, $\mathrm{H}_{2} \mathrm{~S}$ and $\mathrm{NH}_{3}$ measurements) provide an accurate description of chemical compositions or act as surrogates for odour strength, but tell us very little about the perceived effect, whereas olfactometry gives the right human response but is very subjectivity and expensive. The use of non-specific sensor arrays may offer an objective and on-line instrument for assessing olfactive annoyance. Results have shown that sensor array systems can discriminate between different odour sources (wastewater, livestock and landfill). The response patterns from these sources can be significantly different and that the intensity of sensor responses is proportional to the concentration of the volatiles. The correlation of the sensors responses against odour strengths have also shown that reasonable fits can be obtained for a range of odour concentrations (100 $\left.800,000 \mathrm{ou} / \mathrm{m}^{3}\right)$. However, the influence of environmental fluctuations (humidity and temperature) on sensor baselines still remains an obstacle, as well as the need for periodic calibration of the sensory system and the choice of a suitable gas for different environmental odours.
\end{abstract}

\section{KEYWORDS}

Electronic nose; odours; olfactometry; odour assessment; sewage.

\section{INTRODUCTION}

The increasing number of complaints concerning the release of annoyance odours from agricultural, landfills and wastewater treatment facilities has stimulated considerable interest in the measurement of olfactive annoyance (Toogood, 1993; Schulz and van Harreveld, 1996; Vincent and Hobson, 1998). The most method for measuring odour annoyance is based on the dilutions of odorous samples for assessment by human panels (using olfactometry). Although this technique gives the right human sense evaluation and can now by based on a standard methodology, the draft European odour standard (prEN 13725), it is strongly influenced by subjectivity (Bliss et al., 1996), is time consuming, labour intensive and expensive (Hobson and Vincent, 1998). Furthermore, olfactometry laboratories are often remote from the odour source, which make them unsuitable for continuous and on-site assessment of odour annoyance. The second procedure for measuring odours is the chemical analysis of odorous mixtures by chromatographic techniques (such as GC-MS) or the use of surrogates (such as $\mathrm{H}_{2} \mathrm{~S}$ or $\mathrm{NH}_{3}$ ) for determining odour strengths. These methods provide the accurate concentration of specific compounds in a sample and can be used on-site and for continuous assessment, but are limited as their do not provide total olfactive perception. 
The development of sensor array technology so called "electronic noses" for odour classification may offer an objective and on-line instrument for assessing environment odours. Previous commercial sensor array systems were mainly manufactured for laboratory-based applications, however portable and on-line instruments designed for environmental monitoring have recently become available. The aim of this paper is to review the current status of sensor array technology and discuss it potential application to the assessment of olfactive annoyance.

\section{SENSOR ARRAY TECHNOLOGY}

Sensor array systems are analytical instruments that can characterise an odour without reference to its chemical composition. The principle components of a sensor array system are shown in Figure 1. Sensor array systems have been designed to simulate the headspace methodology often employed by analytical and sensory methods for measuring odours (Hodgins and Simmonds, 1995). A range of sensor materials are used in commercial instruments include metal oxides, conducting polymers, surface acoustic wave devices and quartz crystal microbalances (Fenner and Stuetz, 1999). However, their use, specifically to the measurement of environmental odours has been limited (Romain et al., 2000).

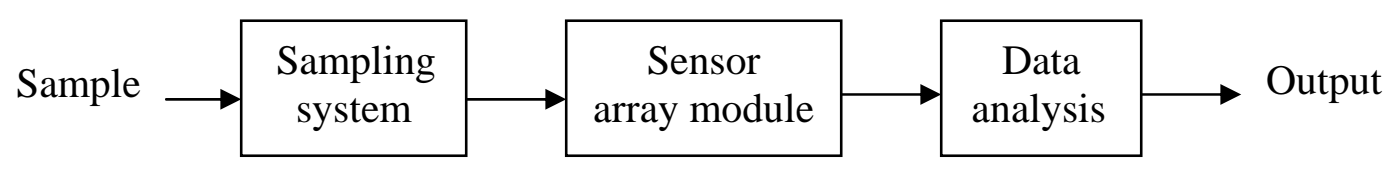

Figure 1 Principal components of a sensor array system

A range of analysis techniques have been used to analyse sensor array data. Output can be displayed using graphical formats to make comparisons between samples, however due to large number of variables (i.e. number of sensors) and samples, pattern recognition techniques (such as multivariate statistics and artificial neural networks) are often employed to reduce the dimensionality of the sensor array data. The relationships between the samples can then be compared and correlated using simple scatter plots. The choice of analysis technique is dependent on the amount and nature of information available and the type of information required from the analysis (i.e. quantitative or qualitative).

\section{ODOUR ASSESSMENT USING SENSOR ARRAYS}

The assessment of annoyance odours from sewage works, agricultural and landfills practises by sensor arrays has until recently been based on the used of laboratory-based instruments (Stuetz and Fenner, 2001). Hobbs et al. (1995) initially showed that a sensor array consisting of 20 conducting polymers could discriminate between the different livestock odours (i.e. pig and chicken slurries), however this early instrument was found to be insensitive when compared to corresponding olfactometry measurements. Persaud et al. (1996) showed that conducting polymers could differentiate between the different components of pig slurry and also found that the intensity of sensor responses for the various components was proportional to the concentration of volatiles being presented to the sensors. Misselbrook et al. (1997) compared the performance of 2 different conducting polymer arrays using odour samples following cattle slurry application to grassland. When the sensor responses were averaged and compared with odour concentrations (from 
olfactometry measurements), reasonable fits were obtained, with about $60 \%$ of the variance in the odour concentrations being explained by the response output. Another significant feature of this study was the concentrations of the odours being considered $\left(100-1000 \mathrm{ou} / \mathrm{m}^{3}\right)$, which was considerably lower than what had previously been reported.

Stuetz et al. (1998) reported on the performance of a 12 sensor conducting polymer array for sewage odour samples from 10 treatment works. Odour samples consisting of a range of odour concentrations $\left(125-781,066 \mathrm{ou} / \mathrm{m}^{3}\right)$ were compared with sensor responses using canonical correlation (a multivariate linear correlation technique). The results showed a lack of a general relationship when all samples were considered (Figure 2), however, when the strongest odour samples were discounted in the correlation analysis, the relationship improved (Figure 3), suggesting that the sensors may become saturated at high odour concentrations (Stuetz et al., 1998). When odour samples from a single treatment works were only considered, a very strong correlation was observed. Similar relationships were also found when the odour potential (Hobson, 1995) of sewage liquors were compared with sensor responses (Stuetz et al., 1999). These findings showed that sewage odour profiles are specific for individual treatment works and for different unit processes within a works, therefore by removing the scatter associated with these different sewage odour compositions, linear correlation relationships could be derived for odour and odour potential samples (Stuetz et al., 1999).

Romain et al. (2000) investigated the performance of a simple metal oxide sensor array to identify annoyance odours from 5 different sources (paint shop, composting facility, wastewater treatment works, rendering plant and printing houses). The odour samples were collected on 4 occasions over a 7 month period in uncontrollable conditions. The principal component analysis and classification of unknown samples (using discriminant analysis) proved that the recognition of the different sample types was not fortuitous, in spite of the potential influence of environmental parameters (such as humidity and temperature) on sensor responses. The study showed that as long as the sampling and learning are carried out under many different ambient conditions, a simple sensor array system can detect and identify olfactive annoyance (Romain et al., 2000). An example of the discriminant classification of 5 different odour sources using a simple metal oxide sensor array is shown in Figure 4.

The above studies have used sensor arrays in laboratory-based conditions to analysis environmental samples. However, in order to understand the effects of environmental parameters on localised odour pollution, it will be necessary to translate these laboratory-based experiences into formats that can be applied to making measurements under variable conditions (Flint et al., 2000). Nicolas et al. (2000) has investigated the application of using a simple portable instrument to detect malodours in the environment, based on 8 tin oxide sensors. Figure 5 shows the plot of classification functions (using discriminant analysis) when the portable detector is moved around a wastewater treatment works, based on a previous learning phase for the 5 different odour sources. The results demonstrate that a portable sensor array can operate continuously without a controlled gas-flow and with suitable training can predict an unknown odour, on the basis of a previously calibrated classification model. Preliminary results have also reported on the quantitative assessment of malodour concentration in the field, using a mobile detector (Nicolas et al., 2000). 


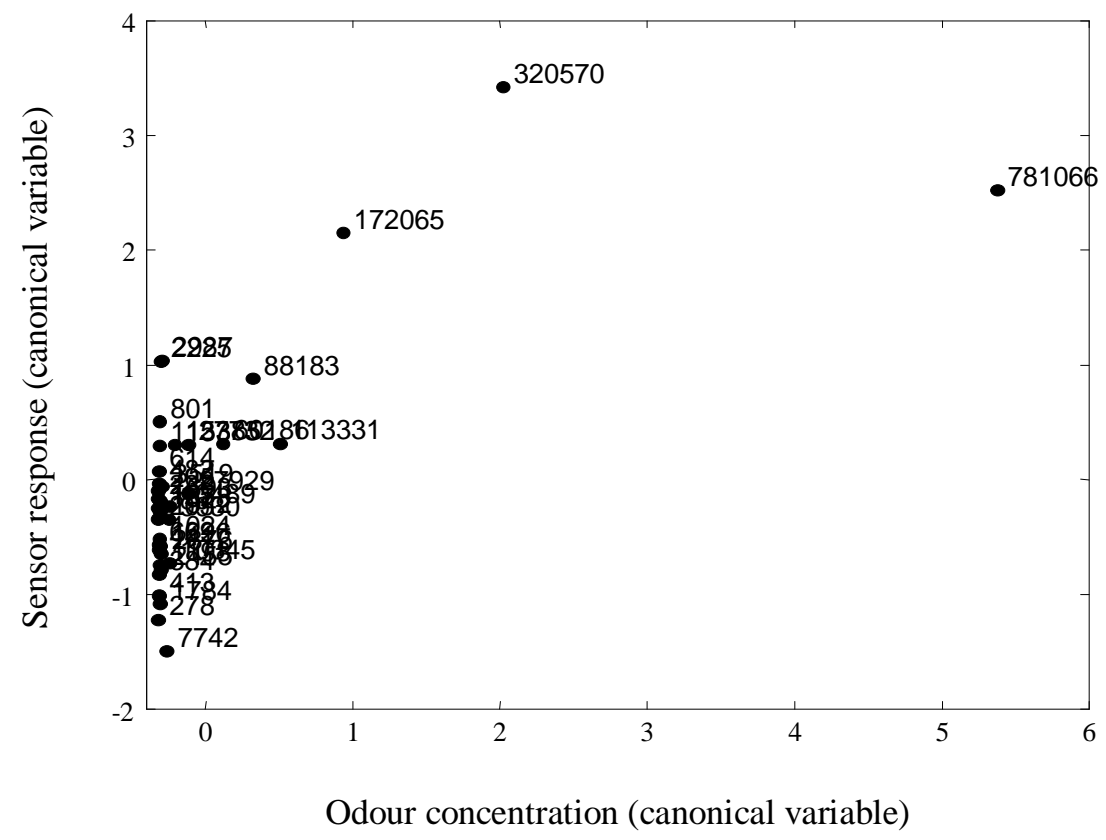

Figure 2 Plot of canonical variables showing the relationship between the sensor responses and odour concentrations (between 125 and $781066 \mathrm{ou} / \mathrm{m}^{3}$ ) for sewage odours from 10 treatment works (Stuetz et al., 1998).

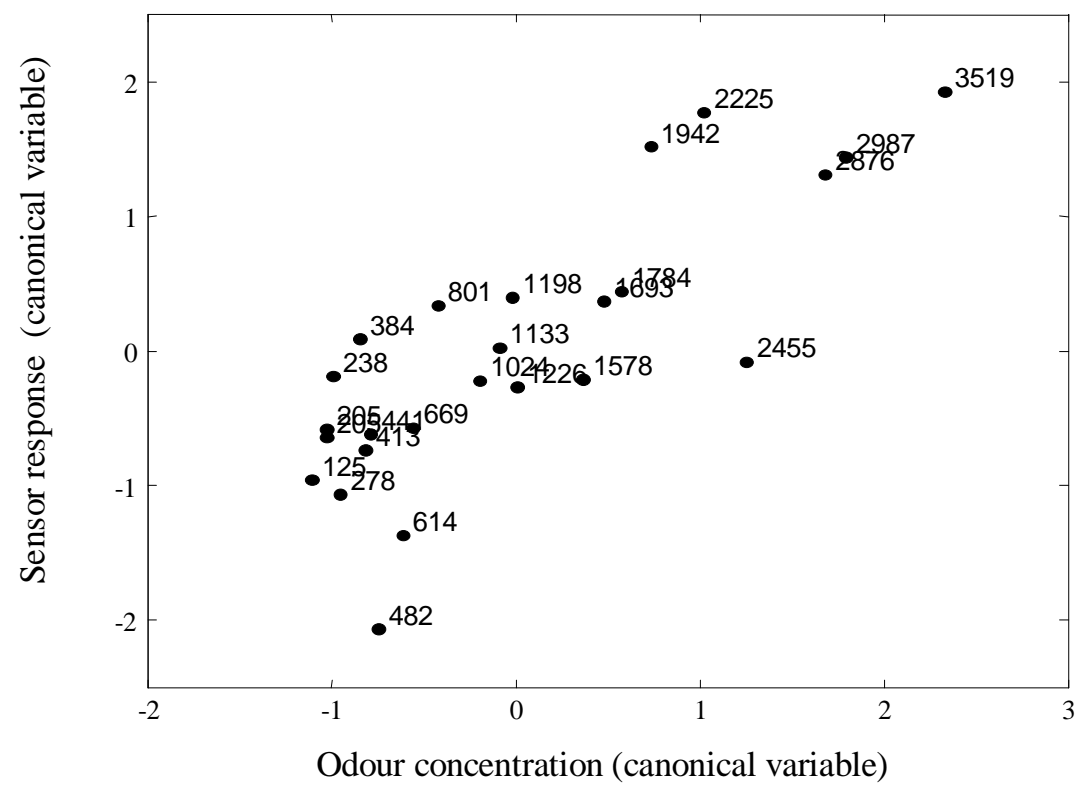

Figure 3 Plot of canonical variables showing the relationship between the sensor responses and odour concentrations (between 125 and $3519 \mathrm{ou} / \mathrm{m}^{3}$ ) for sewage odours from 10 treatment works (Stuetz et al., 1998). 


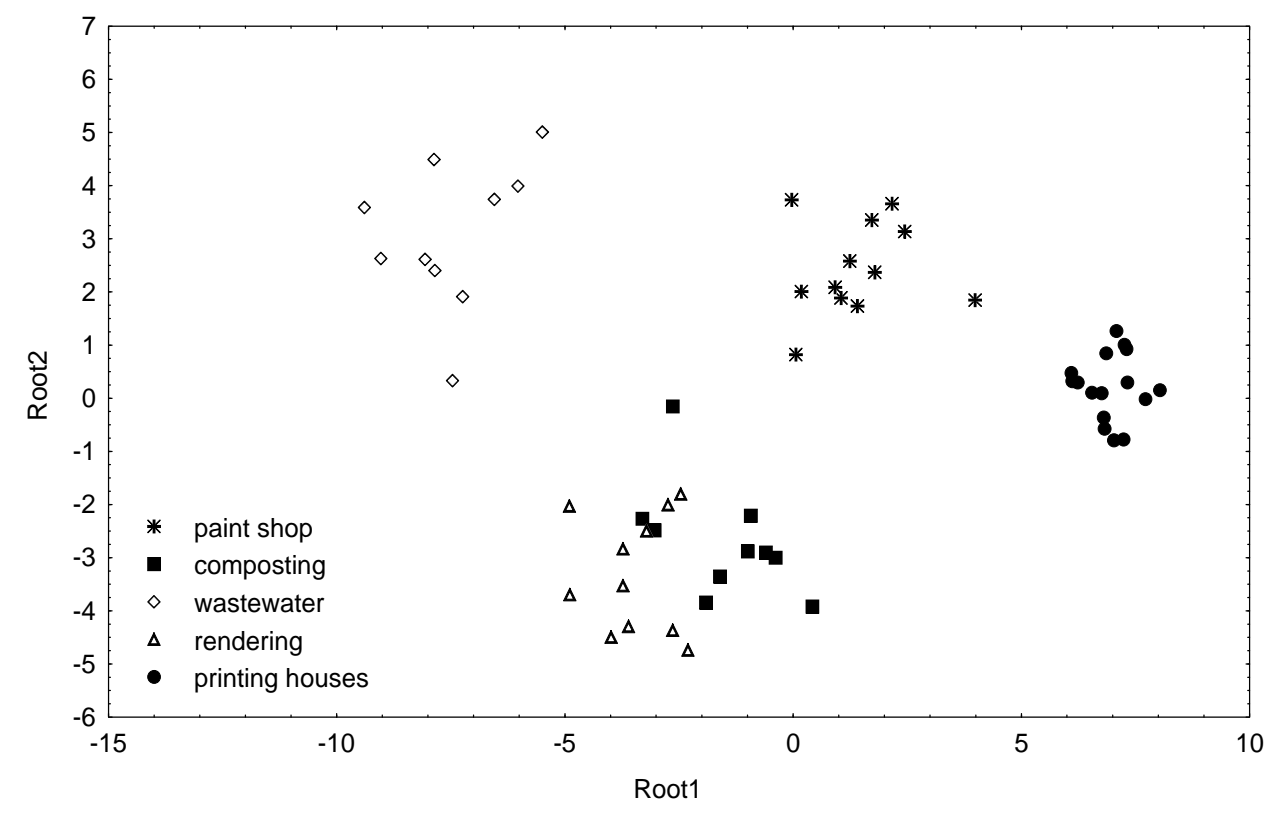

Figure 4 Discriminant analysis of sensor responses for paint shop, composting facilities, wastewater treatment works, rendering plant and printing houses odours (Romain et al., 2000).

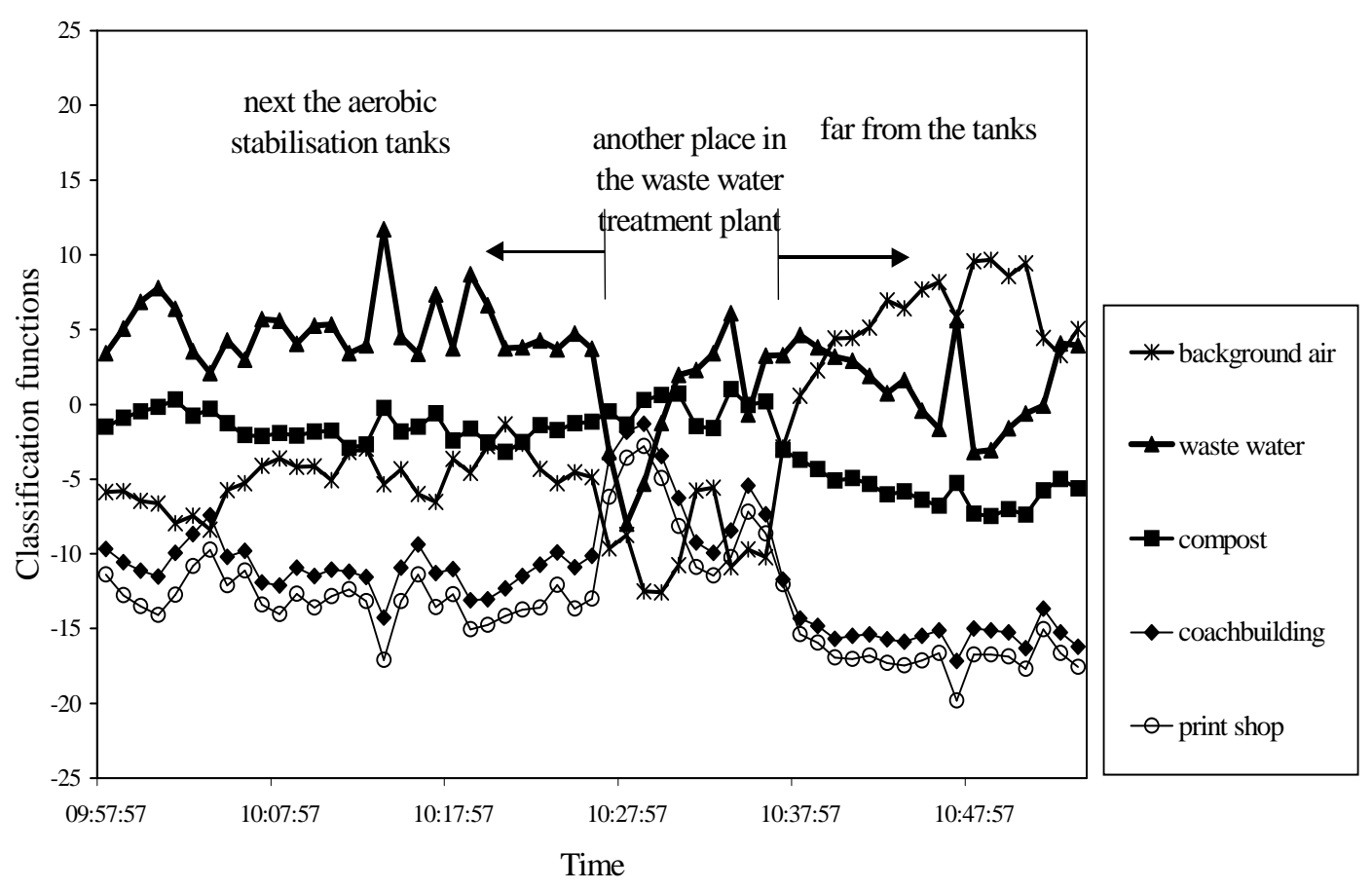

Figure 5 Plot of classification functions when a portable sensor array is moved around a wastewater treatment works, based on a learning phase with 5 odour sources (Nicolas et al., 2000). 


\section{POTENTIAL APPLICATIONS OF SENSOR ARRAYS IN ANNOYANCE ASSESSMENT}

Preliminary studies using both laboratory and simple portable sensor array instruments for assessing environmental odours have been promising. These studies have demonstrated that different annoyance odours can be discriminated and the identity of unknown samples can be predicted using previously calibrated learning models. The influence of environmental parameters (such as air humidity, temperature and airflow) on sensor response baselines has been shown to be important and still remains an obstacle. However, the solution to account for these interference's is dependent on the specific application of the sensor array system (i.e. laboratory or field-based instrument). The effects of variations in ambient temperature and humidity could be incorporated into the design of instruments, through the use the sample pre-treatment systems, such as demonstrated for headspace pretreatment in on-line wastewater monitoring (Bourgeois and Stuetz, 2000). Alternatively, different meteorological parameters could be included in the learning phase to account for as many different environmental conditions in order to be able to predict "odour events" in relation to particular climatic conditions (Nicolas et al., 2000).

Results to date have mainly been based on the assessment of collected environmental odours (from near emission sources), this is largely due to the constraints of using commercial sensor arrays (mainly manufactured for laboratory based application) for assessing environmental odours. The recent commercial development of on-line sensor array systems for process monitoring and portable devices for field-based monitoring will hopefully permit the further assessment of these instruments for environmental monitoring. Potential applications in odour assessment could include the continuous monitoring of odour abatement units and field intensity measurements for the estimation of odour annoyance. However, before these specific applications can become a reality, a number of challenges still need to be overcome.

Further work will need to focus on:

- Understanding and controlling the impact that environmental parameters (such as temperature and humidity) have the validation/prediction of a classification model for continuous odour assessment.

- Improve sensor sensitivity and noise reduction in order to be able to detect local changes in concentration at a resolution that will permit meaningful measurements to be made and reflect actual site conditions.

- Developing a calibration procedure to account for sensor drift by using either a standard gas mixtures for periodic baseline correction or compensation by a calibration algorithm.

- Validation of the quantitative assessment of sensor array responses against olfactometry measurements to confirm comparisons with human perception.

\section{CONCLUSIONS}

The use of laboratory-based sensor array systems for measuring environmental odours have demonstrated that these types of odours can be correlated to the assessment of odour annoyance under controlled environments. However, research is now needed to translate these experiences into the assessment of environmental odours under variable conditions. Preliminary results has shown that although the continuous assessment of olfactive annoyance in the field looks like a challenge, the results to date are very encouraging and the potential of applications is enormous. 


\section{REFERENCES}

Bliss P. J., Schulz T. J., Senger T. and Kaye R. B. (1996). Odour measurement - factors affecting olfactometry panel performance. Wat. Sci. Tech., 34 (3-4), 549-556.

Bourgeois W. and Stuetz R.M. (2000) Measuring wastewater quality using a sensor array: prospects for real-time monitoring. Wat. Sci.Tech., 41 (12), 107-112

Fenner R.A. and Stuetz R.M. (1999) The application of electronic nose technology to environmental monitoring in the water industry. Wat. Environ. Res., 31 (3), 282-289

Flint, T.A., Persuad K.C. and Sneath R.W. (2000) Automated indirect method of ammonia flux measurement for agriculture: effect of incident wind angle on airflow measurements. Sensors and Actuators B 69, 389-396.

Hobbs, P. J., Misselbrock, T. M. and Pain, B. F. (1995) Assessment of odours from livestock wastes by a photoionization detector, an electronic nose, olfactometry and gas chromatographymass spectrometry. J. Agric. Engng. Res., 60, 137-144.

Hobson, J. (1995) ) The odour potential: a new tool for odour management. J. Chart. Inst. Wat. Enviro. Manag., 9: 458-463.

Hodgins D. and Simmonds D. (1995). The electronic nose and its application to the manufacture of food products. J. Auto. Chem., 17(5), 179-185.

Misselbrook TH, Hobbs PJ and Persaud KC. (1997) Use of an electronic nose to measure odour concentrations following application of cattle slurry to glassland. J. Agric. Engng Res., 66, 213-220.

Nicolas J., Romain A.C., Wiertz V., Maternova J. and Andre Ph. (2000) Using a classification model of an electronic nose to assign unknown malodours to environmental sources and to monitor them continuously. Sensors and Actuators B 69, 366-371.

Persaud KC, Khaffaf SM, Sneath RW and Hobbs PJ. (1996) Assessment of conducting polymer odour sensors for agricultural malodour measurements. Chem. Senses, 21, 495-505.

Romain A.C., Nicolas J., Wiertz V., Maternova J. and Andre Ph. (2000) Use of a simple tin oxide sensor array to identify five malodours collected in the field. Sensors and Actuators B 62 , 73-79.

Schulz T. J. and van Harreveld A. P. (1996). International moves towards standardisation of odour measurements using olfactometry. Wat. Sci. Tech., 34 (3-4), 541-547.

Stuetz R. M., Engin G. and Fenner R. A. (1998) Sewage odour measurements using a sensory panel and an electronic nose. Wat. Sci. Tech., 38 (3), 330-335.

Stuetz, R. M., Fenner, R. A. and Engin, G. (1999) Assessment of odours from sewage treatment works by an electronic nose, $\mathrm{H}_{2} \mathrm{~S}$ analysis and olfactometry. Wat. Res. 33, 452-461.

Stuetz R.M. and Fenner R.A. (2001) Odour measurements using sensor arrays. In: Odours in Wastewater Treatment: measurement, modelling and control (R.M. Stuetz and F-B Frechen eds.) pp. 179-198, IWA Publishing, London.

Toogood S. J. (1993). Changing attitudes towards odours - consequences for the water industry. Proc. CIWEM conference on Odour Control and Prevention in the Water Industry, pp. 111.

Vincent A. and Hobson J. (1998) Odour Control. CIWEM Monograph on Best Practice No.2, Terence Dalton Publishing, London, 32p. 